\title{
Relationship Between Renal Function and the Incidence of Adverse Events in Patients With Colorectal Cancer Receiving Oxaliplatin
}

\author{
DAICHI WATANABE ${ }^{1}$, HIRONORI FUJII ${ }^{1}$, YUNAMI YAMADA ${ }^{1}$, HIROTOSHI IIHARA ${ }^{1}$, TAKUMA ISHIHARA ${ }^{2}$, \\ NOBUHISA MATSUHASHI ${ }^{3}$, TAKAO TAKAHASHI ${ }^{3}$, KAZUHIRO YOSHIDA $^{3}$ and AKIO SUZUKI ${ }^{1}$ \\ ${ }^{1}$ Department of Pharmacy, Gifu University Hospital, Gifu, Japan; \\ ${ }^{2}$ Gifu University Hospital, Innovative and Clinical Research Promotion Center, Gifu University, Gifu, Japan; \\ ${ }^{3}$ Department of Surgical Oncology, Gifu University Graduate School of Medicine, Gifu, Japan
}

\begin{abstract}
Background/Aim: To clarify whether renal dysfunction affects the incidence of adverse events associated with oxaliplatin, the present study was designed to investigate the relationship between creatinine clearance $(\mathrm{Ccr})$ and the incidence of oxaliplatin-related adverse events. Patients and Methods: A total of 287 CRC patients who received the first cycle of oxaliplatin-based chemotherapy were eligible. Adverse events, including nausea, vomiting, neutropenia and thrombocytopenia, were graded, and the relationship between $C \mathrm{cr}$ and the incidence of adverse events was examined using multivariable logistic regression analysis. Results: A multivariable analysis indicated that the incidence of grade $\geq 2$ nausea increased, while the incidence of other adverse events tended to be higher, as the Ccr decreased. Particularly, renal dysfunction $(C \mathrm{cr}<60 \mathrm{ml} / \mathrm{min})$ was a significant risk factor for grade $\geq 2$ nausea ( $p=0.042)$. Conclusion: Care should be taken to avoid adverse events associated with oxaliplatin in patients with renal dysfunction.
\end{abstract}

Platinum-based anticancer drugs such as cisplatin and carboplatin are excreted mainly from the kidneys, thus the clearance rates of these compounds are reduced by renal dysfunction $(1,2)$. Anticancer drugs show a narrow therapeutic window and elevation of plasma drug concentration is liable to cause life-threatening adverse events. Therefore, dose adjustment is required based on renal function. Kintzel and

CThis article is freely accessible online.

orrespondence to: Hironori Fujii, Department of Pharmacy, Gifu University Hospital, Yanagido 1-1, Gifu 501-1194, Japan. Tel: +81 582307080, Fax: +81 582307093, e-mail: h_fujii@gifu-u.ac.jp

Key Words: Oxaliplatin, creatinine clearance, adverse events, colorectal cancer, nausea.
Dorr (3) recommended the modifications of doses of anticancer drugs that undergo renal excretion as follows: fraction of dose $=\mathrm{f} \times(\mathrm{Kf}-1)+1$, where $\mathrm{Kf}=$ patient's creatinine clearance (Ccr)/120, where $f$ is the rate of renal excretion of unchanged or active metabolites of the chemotherapy agents. The dose of carboplatin is commonly determined according to the Calvert formula (4): dose $(\mathrm{mg})=$ target AUC $\times(\mathrm{GFR}+25)$.

In contrast, dose adjustment based on renal function is not common for oxaliplatin in clinical practice despite the high renal excretion rate of this compound (5). Oxaliplatin, a thirdgeneration platinum analog, is effective for metastatic colorectal cancer (mCRC), when used in combination with fluoropyrimidines and monoclonal antibodies raised against vascular endothelial growth factor (VEGF) (6-8) or epidermal growth factor receptors (EGFR) $(9,10)$. Moreover, addition of oxaliplatin to fluoropyrimidines was found to be effective as an adjuvant chemotherapy for colon cancer (11-14).

The adverse events associated with oxaliplatin include peripheral neuropathy, myelosuppression, nausea and vomiting $(15,16)$. Takimoto et al. (17) compared the incidence and severity of adverse events associated with oxaliplatin in $37 \mathrm{mCRC}$ patients divided into groups of different renal function, including normal function $(\mathrm{Ccr} \geq 60$ $\mathrm{ml} / \mathrm{min}$ ), mild dysfunction (Ccr 40-59 $\mathrm{ml} / \mathrm{min}$ ), moderate dysfunction (Ccr 20-39 ml/min), and severe dysfunction (Ccr $<20 \mathrm{ml} / \mathrm{min}$ ), and showed that the incidence or severity of adverse events such as nausea, vomiting, fatigue, constipation, peripheral neuropathy and laryngodysesthesia was not different among patients whose Ccr was higher than $20 \mathrm{ml} / \mathrm{min}$. Moreover, they showed in $34 \mathrm{mCRC}$ patients who received $130 \mathrm{mg} / \mathrm{m}^{2}$ of oxaliplatin that there are no significant changes in the incidence rates of oxaliplatinassociated adverse events despite the increase in the area under the concentration time curve (AUC) for oxaliplatin depending on the degree of renal impairment (Ccr>20 $\mathrm{ml} / \mathrm{min}$ ) (18). Nikanjam et al. (19) also reported that the 
clearance of oxaliplatin varies 6.7-fold over the range of serum creatinine values in patients with advanced malignancy who received $60-130 \mathrm{mg} / \mathrm{m}^{2}$ oxaliplatin.

However, it is still uncertain whether or not the incidence or severity of adverse events associated with oxaliplatin is affected by renal function. To further determine the influence of renal dysfunction on the incidence of adverse events associated with oxaliplatin, we here investigated the relationship between $\mathrm{Ccr}$ and the incidence of moderate to severe adverse events, including nausea, vomiting, neutropenia and thrombocytopenia in 287 colorectal cancer (CRC) patients who received a combination chemotherapy of oxaliplatin and fluoropyrimidines.

\section{Patients and Methods}

Patients. A total of 333 patients with stage III-IV CRC received cancer chemotherapy, including oxaliplatin, in our outpatient chemotherapy clinic during a period between January 2010 and December 2017. Among them, 46 patients were excluded from the present study due to the following reasons: reduction of the initial dose of oxaliplatin in 32 patients because of the reduced general status due to aging, and non-adherence of antiemetic medications according to the guideline of Japanese Society of Clinical Oncology in 14 patients (20). Thus, the remaining 287 patients were eligible for the present study. Data were obtained from electronic medical records of our hospital and analyzed retrospectively.

Chemotherapy. Patients were treated with either modified FOLFOX6 regimen every 2 weeks or capecitabine plus oxaliplatin (CapeOX) regimen or S-1 plus oxaliplatin (SOX) regimen every 3 weeks. Modified FOLFOX6 consisted of $2 \mathrm{~h}$ bolus injection of oxaliplatin at $85 \mathrm{mg} / \mathrm{m}^{2}$, $2 \mathrm{~h}$ bolus injection of L-leucovorin at $200 \mathrm{mg} / \mathrm{m}^{2}, 10 \mathrm{~min}$ bolus injection of 5-fluorouracil (5-FU) at $400 \mathrm{mg} / \mathrm{m}^{2}$, followed by continuous infusion of 5 -FU for $46 \mathrm{~h}$ at $2,400 \mathrm{mg} / \mathrm{m}^{2}$. CapeOX consisted of $2 \mathrm{~h}$ bolus injection of oxaliplatin at $130 \mathrm{mg} / \mathrm{m}^{2}$, oral administration of capecitabine at $2,000 \mathrm{mg} / \mathrm{m}^{2}$ twice a day from day 1 to day 15 , followed by rest for 7 days. SOX consisted of $2 \mathrm{~h}$ bolus injection of oxaliplatin at 130 $\mathrm{mg} / \mathrm{m} 2$, oral treatment with S-1 at $80 \mathrm{mg} / \mathrm{m}^{2}$ twice a day from day 1 to day 15 , followed by rest for 7 days. All patients were administered the regular initial dose of chemotherapy drugs in the first cycle.

Assessment of adverse events. The adverse events included hematological toxicities such as neutropenia, thrombocytopenia, and non-hematological toxicities, including nausea and vomiting. In the present study, the relationship between $\mathrm{Ccr}$ and the incidence of adverse events that occurred during 2-3 weeks after the first chemotherapy cycle was investigated. Peripheral neuropathy was excluded from the present study because of the delayed onset of neurotoxicity that appears during later chemotherapy cycles (21). The symptoms of adverse events were graded according to the Common Terminology Criteria for Adverse Events (CTCAE) version 4.0 (22).

Adherence to the Japan Society of Cancer Oncology guideline for the use of antiemetic drugs. All patients received the Japan Society of Cancer Oncology guideline-based antiemetic medication, including the combination of granisetron ( $3 \mathrm{mg} / \mathrm{day}$, intravenously) and dexamethasone $(9.9 \mathrm{mg} /$ day, intravenously) on day 1 , and oral dexamethasone (4 mg/day) on days 2 and $3(20)$.
Table I. Patient demographics.

\begin{tabular}{lrc}
\hline Characteristic & & \\
Number of patients (male/female) & 287 & $(170 / 117)$ \\
Age, median (mini-max) & 62.8 & $(18-86)$ \\
Cancer stage & & \\
Stage III, n, $\%$ & 99 & $34.5 \%$ \\
Stage IV, $\mathrm{n}, \%$ & 188 & $65.5 \%$ \\
Body weight $(\mathrm{kg})$ & 56.0 & $(49.0-62.5)$ \\
Body mass index $(\mathrm{BMI})\left(\mathrm{kg} / \mathrm{m}^{2}\right)$ & 21.4 & $(19.6-23.6)$ \\
Aspartate aminotransferase $(\mathrm{U} / \mathrm{l})$ & 19.0 & $(16.0-26.5)$ \\
Alanine aminotransferase $(\mathrm{U} / \mathrm{l})$ & 17.0 & $(11.0-26.0)$ \\
Serum creatinine $(\mathrm{mg} / \mathrm{dl})$ & 0.67 & $(0.54-0.80)$ \\
Creatinine clearance $(\mathrm{ml} / \mathrm{min})$ & 85.2 & $(68.2-103.7)$ \\
Total bilirubin $(\mathrm{mg} / \mathrm{dl})$ & 0.6 & $(0.5-0.8)$ \\
Neutrophil $(/ \mu \mathrm{l})$ & 3380 & $(2662.5-4565)$ \\
Hemoglobin $(\mathrm{g} / \mathrm{dl})$ & 12.1 & $(10.7-13.2)$ \\
Platelet $(/ \mu \mathrm{l})$ & 24.0 & $(20.1-29.8)$ \\
Chemotherapy regimens & 99 & $34.5 \%$ \\
FOLFOX base $\left(\mathrm{L}-\mathrm{OHP}: 80 \mathrm{mg} / \mathrm{m}^{2}\right), \mathrm{n}, \%$ & 150 & $52.3 \%$ \\
CapeOX base $\left(\mathrm{L}-\mathrm{OHP}: 130 \mathrm{mg} / \mathrm{m}^{2}\right), \mathrm{n}, \%$ & 113 & $39.3 \%$ \\
SOX base $\left(\mathrm{L}-\mathrm{OHP}: 130 \mathrm{mg} / \mathrm{m}^{2}\right), \mathrm{n}, \%$ & 24 & $8.4 \%$ \\
Adjuvant chemotherapy, $\mathrm{n}, \%$ & 99 & $34.5 \%$ \\
With smoking history, $\mathrm{n}, \%$ & 168 & $58.5 \%$ \\
Habitual drinker, $\mathrm{n}, \%$ & 157 & $54.7 \%$ \\
\hline
\end{tabular}

All data indicate median, 25-75th percentiles unless otherwise indicated.

Risk analysis of Ccr associated with adverse events in patients receiving oxaliplatin. Association between $\mathrm{Ccr}$ and adverse events that occurred after oxaliplatin treatment were examined using the multivariable logistic regression analysis model. The model contained adjustment factors such as age, sex, body mass index (BMI), regimen, therapeutic purpose, and drinking history.

Statistical analyses. Data were analyzed using IBM SPSS version 22 (IBM Japan Ltd., Tokyo, Japan), GraphPad Prism version 6.0 (GraphPad Software, San Diego, CA, USA), and R software version 3.5.1 (www.r-project.org). $p$-Values less than 0.05 were considered significant. The demographics of patients are summarized by median with 25 th and 75 th percentiles for continuous variables. Frequencies and percentages are shown for categorical variables.

The multivariable logistic regression analysis was performed to assess the association between $\mathrm{Ccr}$ and adverse events with adjustment for covariates. Age, sex, BMI, regimen, therapeutic purpose and drinking history were chosen as covariates a priori, owing to their expected associations with the adverse events and with Ccr. Non-linear associations between Ccr and adverse events were assessed by using restricted cubic splines in a regression model. The reliability of the regression model was internally validated via a bootstrap method by measuring overfitting, quantified by an optimism parameter in a calibration plot. In the case of overfitting, penalized maximum likelihood estimation was used to allow shrinkage for non-linear effect of Ccr.

Ethics statement. The present study was carried out in accordance with the guideline for human studies adopted by the ethics committee of the Gifu University Graduate School of Medicine and notified by the Japanese government (Institutional review board approval No. 26156). In view of the retrospective nature of the study, the need for 
Watanabe et al: Renal Function and Adverse Events of Oxaliplatin

Table II. The incidence rates of adverse events in all patients who received colorectal cancer treated with oxaliplatin.

\begin{tabular}{|c|c|c|c|c|c|c|}
\hline Adverse events & Grade 1 & Grade 2 & Grade 3 & Grade 4 & Grade $\geq 2$ & Grade $\geq 3$ \\
\hline Nausea, $n,(\%)$ & $38(13.2 \%)$ & $69(24.0 \%)$ & $5(1.7 \%)$ & $0(0 \%)$ & $74(25.8 \%)$ & $5(1.7 \%)$ \\
\hline Vomiting, $\mathrm{n},(\%)$ & $24(8.4 \%)$ & $7(2.4 \%)$ & $3(1.0 \%)$ & $0(0 \%)$ & $10(3.5 \%)$ & $3(1.0 \%)$ \\
\hline Neutropenia, $n,(\%)$ & $5(1.7 \%)$ & $35(12.2 \%)$ & $16(5.6 \%)$ & $12(4.2 \%)$ & $63(22.0 \%)$ & $28(9.8 \%)$ \\
\hline Thrombocytopenia, n, (\%) & $46(16.0 \%)$ & $4(1.4 \%)$ & $2(0.7 \%)$ & $0(0 \%)$ & $6(2.1 \%)$ & $2(0.7 \%)$ \\
\hline
\end{tabular}

informed consent from subjects was not mandated. All procedures performed in studies involving human participants were in accordance with the ethical standards of the institutional and/or national research committee and with the 1964 Helsinki declaration and its later amendments or comparable ethical standards.

\section{Results}

Patients' demographics. Patients' demographics are shown in Table I. Among the 287 studied patients, 170 (59.2\%) were male, and median age was 62.8 years. Stage III and IV cancers were observed in $99(34.5 \%)$ and $188(65.5 \%)$ patients, repsectively. The median Ccr was $85.2 \mathrm{ml} / \mathrm{min}$. Other serum laboratory data, including aspartate aminotransferase, alanine aminotransferase, serum creatinine and total bilirubin were all within the normal range. Patients received modified FOLFOX6 regimen (52.3\%), CapeOX regimen $(39.3 \%)$ or SOX regimen $(8.4 \%)$. Adjuvant chemotherapy was conducted in 99 patients with stage III CRC. A total of 168 patients $(58.5 \%)$ had a history of smoking, while 157 patients $(54.7 \%)$ were habitual drinkers.

The incidence rates of adverse events associated with oxaliplatin. As shown in Table II, the incidence rates of nausea (grade $\geq 2$ ) and vomiting (grade $\geq 1$ ) were $25.8 \%(74 / 287$ ) and $11.8 \%(34 / 287)$, respectively. In other words, the control rates of nausea and vomiting were $74.2 \%$ (213/287) and $87.8 \%$ (252/287), respectively, under the guideline-consistent antiemetic medication. Regarding hematological toxicities, neutropenia (grade $\geq 2$ ) occurred in 63 patients $(22.0 \%$ ), while thrombocytopenia appeared in 6 patients $(2.1 \%)$.

Relationship between Ccr levels and each adverse event. Figure 1A shows the relationship between Ccr levels and predicted probability of grade $\geq 2$ nausea, in which a weak nonlinear relationship was observed $(p=0.25)$. A multivariable logistic regression analysis showed that Ccr levels were a significant risk factor for grade $\geq 2$ nausea [odds ratio $(\mathrm{OR})=0.48,95 \%$ confidence interval $(\mathrm{CI})=0.27-0.87 ; p=0.049]$. Furthermore, there was a tendency for correlation between $\mathrm{Ccr}$ and predicted probability of grade $\geq 1$ vomiting $(\mathrm{OR}=0.48$, $95 \% \mathrm{CI}=0.22-1.04 ; p=0.111)$, grade $\geq 2$ neutropenia $(\mathrm{OR}=0.70$, $95 \% \mathrm{CI}=0.38-1.28 ; p=0.217)$ or grade $\geq 2$ thrombocytopenia $(\mathrm{OR}=0.42,95 \% \mathrm{CI}=0.08-2.19 ; p=0.577)$ (Figure 1B-D).
Comparison of $<60 \mathrm{ml} / \mathrm{min}$ Ccr levels and $\geq 60 \mathrm{ml} / \mathrm{min}$ for risk of nausea. A risk for grade $\geq 2$ nausea was evaluated between patients with normal Ccr levels and those whose Ccr levels were less than $60 \mathrm{ml} / \mathrm{min}$. A multivariable logistic regression analysis indicated that $\mathrm{Ccr}<60 \mathrm{~m} / \mathrm{min}$ was associated with 2- to 3 -fold higher odds of nausea $(\mathrm{OR}=2.61$, 95\% CI=1.04-6.55; $p=0.042$ ).

\section{Discussion}

In the present study, we investigated the relationship between Ccr and the incidence of adverse events, including nausea, vomiting, neutropenia and thrombocytopenia in CRC patients after receiving the first cycle of oxaliplatin plus fluoropyrimidine chemotherapy.

We found that the incidence of grade $\geq 2$ nausea was negatively correlated with Ccr levels. A multivariable logistic regression analysis indicated that the OR adjusted by age, gender, body mass index (BMI), chemotherapy regimen, therapeutic purpose, and drinking history, was 0.48 (95\%CI=0.27-0.87; $p=0.049)$. Moreover, $\mathrm{Ccr}<60 \mathrm{ml} / \mathrm{min}$ was found to be a significant risk for grade $\geq 2$ nausea $(\mathrm{OR}=2.61$; 95\% CI=1.04-6.55; $p=0.042$ ). Yamazaki $\mathrm{K}$ et al. reported that the incidence of grade 3 CapeOX-related adverse events was higher in the Ccr-L (patients with a $\mathrm{Ccr}<50 \mathrm{ml} / \mathrm{min}$ ) group than in the $\mathrm{Ccr}-\mathrm{H}$ (patients with a $\mathrm{Ccr} \geq 50 \mathrm{ml} / \mathrm{min}$ ) group (Ccr-L 42.3\% vs. Ccr-H 31.3\%), and grade 3 nausea was also increased (Ccr-L 5.2\% vs. Ccr-H 1.4\%) (23). The incidence of vomiting tended to be inversely related with $\mathrm{Ccr}(\mathrm{OR}=0.48$; $95 \% \mathrm{CI}=0.22-1.04 ; p=0.111)$. In the present study, all patients were pretreated with granisetron and dexamethasone for prevention of nausea and vomiting according to the clinical practice guideline of the Japan Society of Cancer Oncology. As a result, the control of nausea and vomiting seemed to be almost sufficient since the rates of no grade $\geq 2$ nausea and no vomiting were $74.2 \%$ and $87.8 \%$, respectively. Therefore, it was notable that the probability of nausea showed an inverse correlation with Ccr even under such a condition. Our data on the incidence of nausea and vomiting were comparable to those reported by Nishimura et al. (24) who showed in CRC patients receiving oxaliplatin that the incidence rates of significant nausea and vomiting in the first cycle were $19.1 \%$ 


\section{A. Nausea (grade $\geq 2$ )}

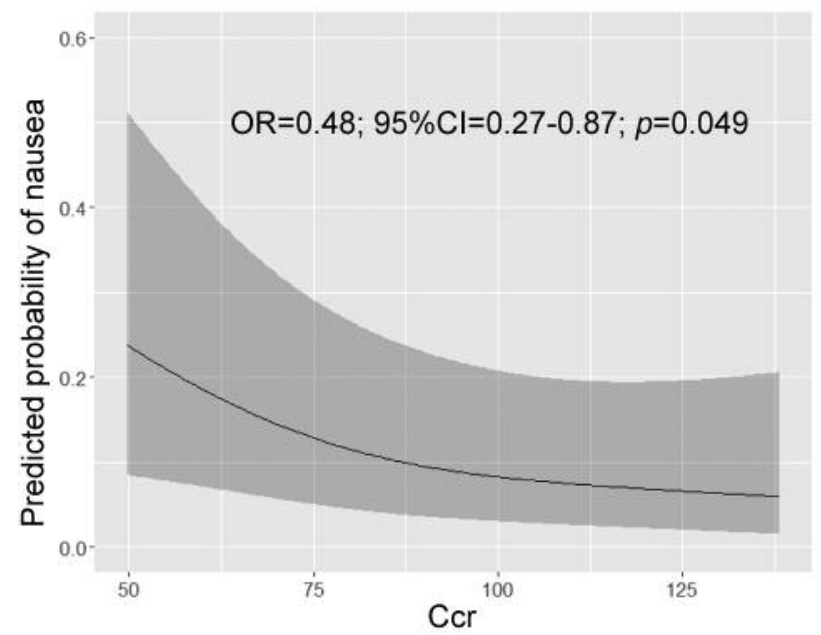

C. Neutropenia $($ grade $\geq 2$ )

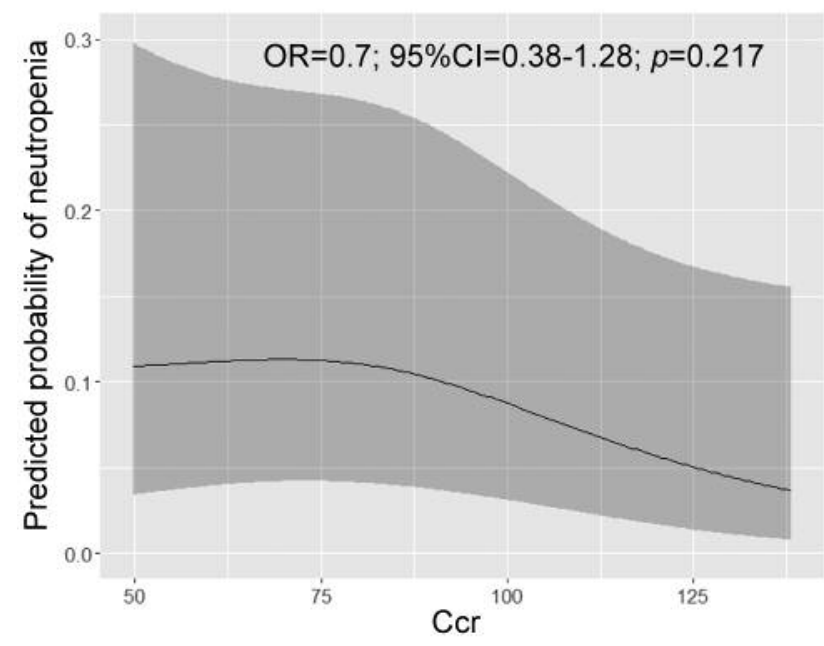

B. Vomiting $($ grade $\geq 1)$

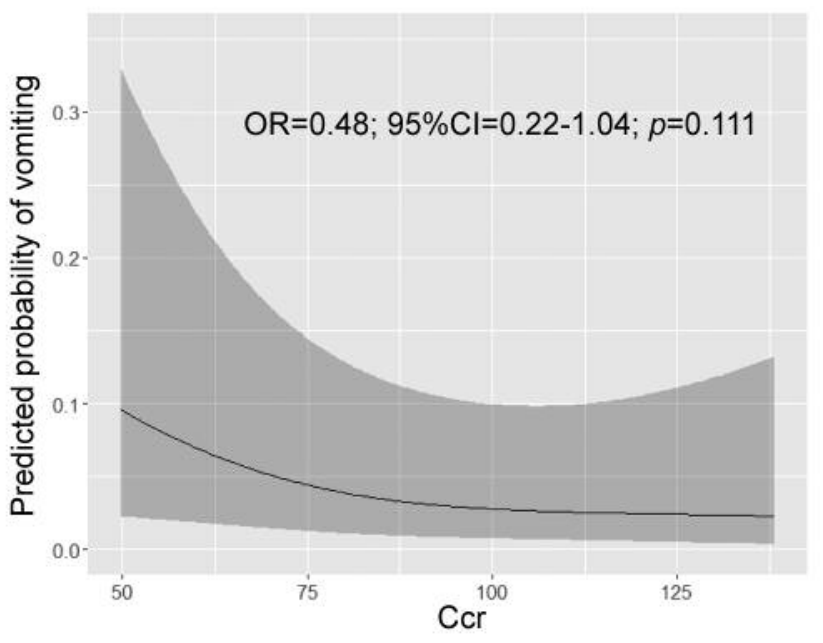

D. Thrombocytopenia (grade $\geq 2$ )

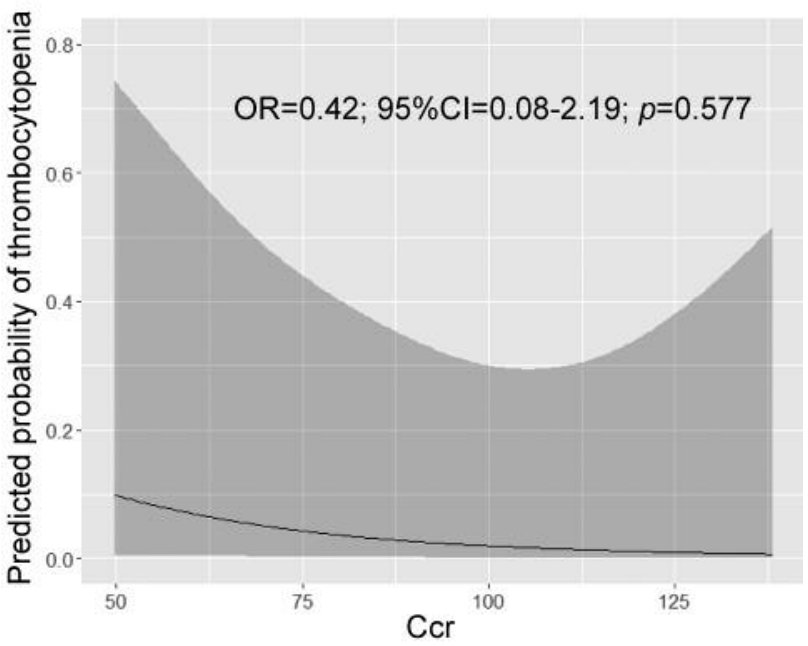

Figure 1. Relationship between predicted probability of grade $\geq 2$ nausea (A), grade $\geq 1$ vomiting (B), grade $\geq 2$ neutropenia (C) and grade $\geq 2$ thrombocytopenia $(D)$ and $C c r$ by using restricted cubic splines in a regression model in patients receiving oxaliplatin. Odds ratio (OR) and $95 \%$ confidence interval (CI) for the incidence of adverse events in the first quartile of Ccr to that in the third quartile of Ccr are shown.

and $16.4 \%$, respectively, under antiemetic medication including granisetron and dexamethasone. The present data were also consistent with our previous data reported in CRC patients receiving moderate emetic-risk chemotherapy where the rates of significant nausea and vomiting were $26.6 \%$ and $5.2 \%$, respectively (25). Takimoto et al. (18) reported on the pharmacokinetics of oxaliplatin in cancer patients with impaired renal function. They showed that renal dysfunction prolongs the half-life of $\beta$ phase $\left(\mathrm{t}_{1 / 2} \beta\right)$ and increases AUC of plasma ultrafiltrate platinum, in which $\mathrm{t}_{1 / 2} \beta$ and AUC were $14.0 \mathrm{~h}$ and $16.4 \mu \mathrm{g} / \mathrm{h} / \mathrm{ml}$, respectively for normal renal function (Ccr>60 ml/min), $20.3 \mathrm{~h}$ and $39.7 \mu \mathrm{g} / \mathrm{h} / \mathrm{ml}$, respectively for mild renal dysfunction (Ccr 40-59 ml/min), and $29.2 \mathrm{~h}$ and $44.6 \mu \mathrm{g} / \mathrm{h} / \mathrm{ml}$, respectively, for moderate renal dysfunction (Ccr 20-39 ml/min). Merkel et al. (26) analysed patients with metastatic gastrointestinal cancer who received 4-day chemotherapeutic regimen consisting of a 12-h chronomodulated infusion of oxaliplatin $\left(25 \mathrm{mg} / \mathrm{m}^{2}\right)$ followed by a 12 -h chronomodulated infusion of 5-fluorouracil (750 $\left.\mathrm{mg} / \mathrm{m}^{2}\right)$ and sodium folinate $\left(150 \mathrm{mg} / \mathrm{m}^{2}\right)$ daily and found that the incidence of nausea and vomiting but not diarrhea is significantly associated with the pharmacokinetics of ultrafiltrate platinum. Taken together, it is suggested that the risk for nausea and vomiting is elevated in patients with 
impaired renal function due to an increase in AUC of ultrafiltrate platinum. Our present data on the relationship between $\mathrm{Ccr}$ and the incidence of nausea are consistent with this notion.

Thus, care should be taken to avoid nausea by the addition of other types of antiemetic drugs such as $\mathrm{NK}_{1}$ receptor antagonist or olanzapine to the standard antiemetic medication in the case of patients with reduced renal function $(\mathrm{Ccr}<60 \mathrm{ml} / \mathrm{min}$ ) who receive oxaliplatin, although the dose adjustment of oxaliplatin is not common for patients with renal dysfunction in clinical settings.

However, there was a weak tendency for an insignificant negative relationship between $\mathrm{Ccr}$ and the probability of neutropenia $(\mathrm{OR}=0.70 ; 95 \% \mathrm{CI}=0.38-1.28 ; p=0.217)$ or thrombocytopenia $(\mathrm{OR}=0.42 ; 95 \% \mathrm{CI}=0.08-2.19 ; p=0.577)$.

There are several limitations in the present study: First, this study was retrospective and analysed data of a single center. Second, the adverse events were evaluated during the first cycle of chemotherapy. Third, the present study contained no pharmacokinetic data.

In conclusion, we determined whether reduction in renal function affects the incidence or severity of oxaliplatinassociated adverse events in CRC patients. There was a significant relationship between the Ccr levels and the incidence of grade $\geq 2$ nausea, although no significant relationship was observed between $\mathrm{Ccr}$ and the incidence of vomiting, neutropenia or thrombocytopenia. In addition, patients with impaired renal function ( $\mathrm{Ccr}<60 \mathrm{ml} / \mathrm{min}$ ) had higher risk for grade $\geq 2$ nausea $(\mathrm{OR}=2.61$; 95\% CI $=1.04$ $6.55, p=0.042)$. Therefore, care should be taken to avoid or alleviate adverse events in patients with renal dysfunction who receive oxaliplatin.

\section{Conflicts of Interest}

K. Yoshida has received honoraria for lectures from Chugai Pharmaceutical Co., Ltd., Taiho. Pharmaceutical Co., Ltd., Takeda Pharmaceutical Co., Ltd., Eli Lilly and Company, Yakult Honsha Co., Ltd., Merck Sharp \& Dohmegrants Co., Ltd., Daiichi Sankyo Co., Ltd., Ono Pharmaceutical Co., Ltd., Merck Serono Co., Ltd., Johnson \& Johnson Co., Ltd., Covidien Co., Ltd., Eisai Co., Ltd., Otsuka Pharmaceutical Co., Ltd., Sanofi K.K., Nippon Kayaku Co., Ltd., Asahi Kasei Co., Ltd., Tsumura Co., Ltd., EA Pharma Co., Ltd., Bayer Yakuhin Co., Ltd., Olympus Co., Ltd., Terumo Co., Ltd., Bristol-Myers Squibb Co., Ltd., Denka Co., Ltd., Teijin Co., Ltd., SBI Pharmaceuticals Co., Ltd., Intuitive Surgical Co., Ltd., Novartis Pharma K.K., Pfizer Inc.; and research funding from Chugai Pharmaceutical Co., Ltd., Taiho Pharmaceutical Co., Ltd., Takeda Pharmaceutical Co., Ltd., Eli Lilly and Company, Yakult Honsha Co., Ltd., Merck Sharp \& Dohmegrants Co., Ltd., Daiichi Sankyo Co., Ltd., Ono Pharmaceutical Co., Ltd., Merck Serono Co., Ltd., Johnson \& Johnson Co., Ltd., Covidien Co., Ltd., Eisai Co., Ltd., Otsuka Pharmaceutical Co., Ltd., Sanofi K.K., Nippon Kayaku Co., Ltd., Asahi Kasei Co., Ltd., Tsumura Co., Ltd., Kyowa Hakko Kirin Co., Ltd., Astellas Pharma Co., Ltd., Toyama Chemical Co.,
Ltd., Kinetic Concepts Co., Ltd., Abbott Japan Co., Ltd., Toray Industries, Co., Ltd. outside the submitted work. Takahashi has received honoraria for lectures from Takeda Pharmaceutical Co., Ltd. and Sanofi Co., Ltd. The other authors have no conflicts of interest to declare.

\section{Authors' Contributions}

H.F. conceived the study concepts. D.W. and H.F. conducted the claim data analysis. H.F. and T.I. performed the statistical analyses. Y.Y. and H.I. provided technical support. N.M., T.T. and K.Y. contributed to the interpretation of data and assisted in the preparation of the manuscript. D.W., H.F., and Y.Y. drafted the initial manuscript. H.I., T.I., N.M., T.T, K.Y., and A.S. conducted critical revision of the manuscript. All Authors reviewed the manuscript.

\section{References}

1 Egorin MJ, Van Echo DA, Tipping SJ, Olman EA, Whitacre MY, Thompson BW and Aisner J: Pharmacokinetics and dosage reduction of cis-diammine(1,1-cyclobutanedicarboxylato) platinum in patients with impaired renal function. Cancer Res 44: 5432-5438, 1984. PMID: 6386150.

2 Harland SJ, Newell DR, Siddik ZH, Chadwick R, Calvert AH and Harrap KR: Pharmacokinetics of cis-diammine-1,1-cyclobutane dicarboxylate platinum (II) in patients with normal and impaired renal function. Cancer Res 44: 1693-1697, 1984. PMID: 6367971.

3 Kintzel PE and Dorr RT: Anticancer drug renal toxicity and elimination: dosing guidelines for altered renal function. Cancer Treat Rev 21: 33-64, 1995. PMID: 7859226. DOI: 10.1016/03057372(95)90010-1

4 Calvert AH, Newell DR, Gumbrell LA, O'Reilly S, Burnell M, Boxall FE, Siddik ZH, Judson IR, Gore ME and Wiltshaw E: Carboplatin dosage: prospective evaluation of a simple formula based on renal function. J Clin Oncol 7: 1748-1756, 1989. PMID: 2681557. DOI: 10.1200/JCO.1989.7.11.1748

5 Shirao K, Matsumura Y, Yamada Y, Muro K, Gotoh M, Boku N, Ohtsu A, Nagashima F, Sano Y, Mutoh M and Tanigawara Y: Phase I study of single-dose oxaliplatin in Japanese patients with malignant tumors. Jpn J Clin Oncol 36: 295-300, 2006. PMID: 16702162. DOI: $10.1093 /$ jjco/hyl016

6 Saltz LB, Clarke S, Díaz-Rubio E, Scheithauer W, Figer A, Wong R, Koski S, Lichinitser M, Yang TS, Rivera F, Couture F, Sirzén $\mathrm{F}$ and Cassidy J: Bevacizumab in combination with oxaliplatinbased chemotherapy as first-line therapy in metastatic colorectal cancer: A randomized phase III study. J Clin Oncol 26: 20132019, 2008. PMID: 18421054. DOI: 10.1200/JCO.2007.14.9930

7 Cassidy J, Clarke S, Díaz-Rubio E, Scheithauer W, Figer A, Wong R, Koski S, Lichinitser M, Yang TS, Rivera F, Couture F, Sirzén F and Saltz L: Randomized phase III study of capecitabine plus oxaliplatin compared with fluorouracil/folinic acid plus oxaliplatin as first-line therapy for metastatic colorectal cancer. J Clin Oncol 26: 2006-2012, 2008. PMID: 18421053. DOI: $10.1200 / J C O .2007 .14 .9898$

8 Yamada Y, Takahari D, Matsumoto H, Baba H, Nakamura M, Yoshida K, Yoshida M, Iwamoto S, Shimada K, Komatsu Y, Sasaki Y, Satoh T, Takahashi K, Mishima H, Muro K, Watanabe M, Sakata Y, Morita S, Shimada Y and Sugihara K: Leucovorin, fluorouracil, and oxaliplatin plus bevacizumab versus $\mathrm{S}-1$ and 
oxaliplatin plus bevacizumab in patients with metastatic colorectal cancer (SOFT): an open-label, non-inferiority, randomised phase 3 trial. Lancet Oncol 14: 1278-1286, 2013. PMID: 24225157. DOI: 10.1016/S1470-2045(13)70490-X

9 Bokemeyer C, Bondarenko I, Makhson A, Hartmann JT, Aparicio J, de Braud F, Donea S, Ludwig H, Schuch G, Stroh C, Loos AH, Zubel A and Koralewski P: Fluorouracil, leucovorin, and oxaliplatin with and without cetuximab in the first-line treatment of metastatic colorectal cancer. J Clin Oncol 27: 663-671, 2009. PMID: 19114683. DOI: 10.1200/JCO.2008.20.8397

10 Douillard JY, Siena S, Cassidy J, Tabernero J, Burkes R, Barugel M, Humblet Y, Bodoky G, Cunningham D, Jassem J, Rivera F, Kocákova I, Ruff P, Błasińska-Morawiec M, Šmakal M, Canon JL, Rother M, Oliner KS, Wolf M and Gansert J: Randomized, phase III trial of panitumumab with infusional fluorouracil, leucovorin, and oxaliplatin (FOLFOX4) versus FOLFOX4 alone as first-line treatment in patients with previously untreated metastatic colorectal cancer: the PRIME study. J Clin Oncol 28: 4697-4705, 2010. PMID: 20921465. DOI: 10.1200/JCO.2009.27.4860

11 André T, Boni C, Mounedji-Boudiaf L, Navarro M, Tabernero J, Hickish T, Topham C, Zaninelli M, Clingan P, Bridgewater J, Tabah-Fisch I and de Gramont A; Multicenter International Study of Oxaliplatin/5-Fluorouracil/Leucovorin in the Adjuvant Treatment of Colon Cancer (MOSAIC) Investigators. Oxaliplatin, fluorouracil, and leucovorin as adjuvant treatment for colon cancer. N Engl J Med 350: 2343-2351, 2004. PMID: 15175436. DOI: 10.1056/NEJMoa032709

12 André T, Boni C, Navarro M, Tabernero J, Hickish T, Topham C, Bonetti A, Clingan P, Bridgewater J, Rivera F and de Gramont A: Improved overall survival with oxaliplatin, fluorouracil, and leucovorin as adjuvant treatment in stage II or III colon cancer in the MOSAIC trial. J Clin Oncol 27: 31093116, 2009. PMID: 19451431. DOI: 10.1200/JCO.2008.20.6771

13 Haller DG, Tabernero J, Maroun J, de Braud F, Price T, Van Cutsem E, Hill M, Gilberg F, Rittweger K and Schmoll HJ: Capecitabine plus oxaliplatin compared with fluorouracil and folinic acid as adjuvant therapy for stage III colon cancer. J Clin Oncol 29: 1465-1471, 2011. PMID: 21383294. DOI: 10.12 00/JCO.2010.33.6297

14 Schmoll HJ, Cartwright T, Tabernero J, Nowacki MP, Figer A, Maroun J, Price T, Lim R, Van Cutsem E, Park YS, McKendrick J, Topham C, Soler-Gonzalez G, de Braud F, Hill M, Sirzén F and Haller DG: Phase III trial of capecitabine plus oxaliplatin as adjuvant therapy for stage III colon cancer: a planned safety analysis in 1,864 patients. J Clin Oncol 25: 102-109, 2007. PMID: 17194911. DOI: 10.1200/JCO.2006.08.1075

15 Mani S, Graham MA, Bregman DB, Ivy P and Chaney SG: Oxaliplatin: a review of evolving concepts. Cancer Invest 20: 246-263, 2002. PMID: 11901545. DOI: 10.1081/cnv-120001152

16 Misset JL: Oxaliplatin in practice. Br J Cancer 77: 4-7, 1998. PMID: 9647612. DOI: 10.1038/bjc.1998.428

17 Takimoto CH, Remick SC, Sharma S, Mani S, Ramanathan RK, Doroshow J, Hamilton A, Mulkerin D, Graham M, Lockwood GF, Ivy P, Egorin M, Schuler B, Greenslade D, Goetz A, Knight R, Thomas R, Monahan BP, Dahut W and Grem JL; National Cancer Institute Organ Dysfunction Working Group Study. Doseescalating and pharmacological study of oxaliplatin in adult cancer patients with impaired renal function: a National Cancer Institute Organ Dysfunction Working Group Study. J Clin Oncol 21: 26642672, 2003. PMID: 12860942. DOI: 10.1200/JCO.2003.11.015
18 Takimoto CH, Graham MA, Lockwood G, Ng CM, Goetz A, Greenslade D, Remick SC, Sharma S, Mani S, Ramanathan RK, Synold TW, Doroshow JH, Hamilton A, Mulkerin DL, Ivy P, Egorin MJ and Grem JL: Oxaliplatin pharmacokinetics and pharmacodynamics in adult cancer patients with impaired renal function. Clin Cancer Res 13: 4832-4839, 2007. PMID: 17699862. DOI: 10.1158/1078-0432.CCR-07-0475

19 Nikanjam M, Stewart CF, Takimoto CH, Synold TW, Beaty O, Fouladi $M$ and Capparelli EV: Population pharmacokinetic analysis of oxaliplatin in adults and children identifies important covariates for dosing. Cancer Chemother Pharmacol 75: 495503, 2015. PMID: 25557868. DOI: 10.1007/s00280-014-2667-6

20 Takeuchi H, Saeki T, Aiba K, Tamura K, Aogi K, Eguchi K, Okita K, Kagami Y, Tanaka R, Nakagawa K, Fujii H, Boku N, Wada M, Akechi T, Udagawa Y, Okawa Y, Onozawa Y, Sasaki H, Shima Y, Shimoyama N, Takeda M, Nishidate T, Yamamoto A, Ikeda T and Hirata K: Japanese Society of Clinical Oncology clinical practice guidelines 2010 for antiemesis in oncology: executive summary. Int J Clin Oncol 21: 1-12, 2016. PMID: 26081252. DOI: $10.1007 / \mathrm{s} 10147-015-0852-1$

21 Kokotis P, Schmelz M, Kostouros E, Karandreas N and Dimopoulos MA: Oxaliplatin-induced neuropathy: A long-term clinical and neurophysiologic follow-up study. Clin Colorectal Cancer 15: e133140, 2016. PMID: 27038553. DOI: 10.1016/j.clcc.2016.02.009

22 U.S. Department of Health and Human Services, National Institutes of Health National Cancer Institute (2009) Common Terminology Criteria for Adverse Events (CTCAE) Version 4.0. Available at: https://www.eortc.be/services/doc/ctc/

23 Yamazaki K, Matsumoto S, Imamura CK, Yamagiwa C, Shimizu A and Yoshino T: Clinical impact of baseline renal function on safety and early discontinuation of adjuvant capecitabine plus oxaliplatin in elderly patients with resected colon cancer: a multicenter post-marketing surveillance study. Jpn J Clin Oncol pii: hyz149, 2019. PMID: 31665356. DOI: 10.1093/jjco/hyz149

24 Nishimura J, Satoh T, Fukunaga M, Takemoto H, Nakata K, Ide Y, Fukuzaki T, Kudo T, Miyake Y, Yasui M, Morita S, Sakai D, Uemura M, Hata T, Takemasa I, Mizushima T, Ohno Y, Yamamoto H, Sekimoto M, Nezu R, Doki Y and Mori M; Multi-center Clinical Study Group of Osaka, Colorectal Cancer Treatment Group (MCSGO). Combination antiemetic therapy with aprepitant/fosaprepitant in patients with colorectal cancer receiving oxaliplatin-based chemotherapy (SENRI trial): a multicentre, randomised, controlled phase 3 trial. Eur J Cancer 51: 1274-1282, 2015. PMID: 25922233. DOI: 10.1016/j.ejca.2015.03.024

25 Fujii $\mathrm{H}$, Iihara $\mathrm{H}$, Ishihara M, Takahashi T, Yoshida $\mathrm{K}$ and Itoh Y: Improvement of adherence to guidelines for antiemetic medication enhances emetic control in patients with colorectal cancer receiving chemotherapy of moderate emetic risk. Anticancer Res 33: 5549-5556, 2013. PMID: 24324096.

26 Merkel U, Farker K, Wedding U, Roskos M, Hippius M, Höffken $\mathrm{K}$ and Hoffmann A: Pharmacokinetics of oxaliplatin and nonhematological toxicity in metastatic gastrointestinal cancer patients treated with chronomodulated oxaliplatin, 5-FU and sodium folinate in a pilot investigation. Int J Clin Pharmacol Ther 44: 128-134, 2006. PMID: 16550735. DOI: 10.5414/cpp44128

Received October 27, 2019

Revised November 20, 2019 Accepted November 21, 2019 